\title{
Dynamic corrosion mechanical properties of magnesium alloys with Erbium in the chloride ions environment
}

\author{
Miao Yang ${ }^{1}$, Liyun Xing ${ }^{2,}{ }^{*}$, Xiaobo Liu $^{3}$, Yuqi Dong ${ }^{3}$, and Jiliang Jin ${ }^{2}$ \\ ${ }^{1}$ Engineering Training Center, Beihua University, Xinshan Street, 132021 Jilin, China \\ ${ }^{2}$ College of Electrical and Information Engineering, Beihua University, Xinshan Street, 132021 Jilin, \\ China \\ ${ }^{3}$ College of Mechanical Engineering, Beihua University, Xinshan Street, 132021 Jilin, China
}

\begin{abstract}
The X-ray diffraction (XRD), scanning electron microscope (SEM), weight loss corrosion rate, corrosion residual strength (CRS), and slow strain rate tensile (SSRT) methods were used to study the effects of the addition of rare earth Erbium (Er) on the dynamic corrosion mechanical properties of the AM50 magnesium alloy. The results show that after Er was added, a new phase of Al3Er appeared and the microstructure was refined. The corrosion resistance of rare earth Er addition to the alloy was $0.5 \%>$ $1.5 \%>1.0 \%>0$. Furthermore, the corrosion rates decreased in $432 \mathrm{~h}$. The CRS results within $168 \mathrm{~h}$ show that the strength after an addition of $0.5 \% \mathrm{Er}$ was the highest and the decline rate was the smallest. According to the shape of the tensile curve of CRS and the morphology of the tensile fracture, the addition of rare earth Er did not change the fracture form of the alloy, which remained as quasi-cleavage.
\end{abstract}

Keywords: Magnesium alloy, Corrosion, Rare earth Erbium, Corrosion residual strength.

\section{Introduction}

Due to their high specific strength and stiffness, magnesium alloys are increasingly used in the aerospace and automotive industries[1-5]. However, the poor corrosion resistance of magnesium alloys limits their application[6-9]. Many methods such as surface modification, purification and alloying have been chosen in order to improve the corrosion resistance[1012]. Furthermore, Rare earth alloying has been proved to be an effective means to improve the corrosion and mechanical properties of magnesium alloys[13-15]. After the material corrodes, its strength gradually declines until it broken. Therefore, the strength of the material after corrosion is called Corrosion residual strength (CRS)[16, 17].The study of residual strength of corrosion is helpful to predict the service life of materials and avoid loss due to unexpected material failure. In addition, if it can establish the prediction method of CRS will promote and popularize the application of magnesium alloy[18, 19]. In this paper, the AM50

\footnotetext{
*Corresponding author: xingliyun@beihua.edu.cn
} 
magnesium alloy was modified with different amounts of rare earth element Erbium (Er) to evaluate the influence on the dynamic corrosion mechanical properties under $\mathrm{Cl}$ ion environment.

\section{Experimental procedures}

\subsection{Alloy preparation}

In the casting process, commercial AM50, Mg-Er (mass fraction 20\%) intermediate alloy, and industrial pure aluminum were used. The target addition amount of Er was the mass fraction $0 \%, 0.5 \%, 1 \%$, and $1.5 \%$, respectively. In the smelting process, the $5 \mathrm{~kW}$ well-type electric furnace was used, and pure argon gas was used for protecting the melted liquid during the whole process. First, the AM50 magnesium alloy was placed in a graphite crucible. Then, at the temperature of $700{ }^{\circ} \mathrm{C}$, the $\mathrm{Mg}-\mathrm{Er}$ intermediate alloy and the pure aluminum were put into the melted liquid. After being homogenized at $710{ }^{\circ} \mathrm{C}$ for 20 minutes, the melted liquid was poured into a pre-heated iron mold at $150{ }^{\circ} \mathrm{C}$, the size of which was $200 \times 120 \times 12 \mathrm{~mm}$. The chemical compositions of the samples tested by the Inductively Coupled Plasma-Atomic Emission Spectrometry (ICP-AES) method are listed in Table 1.

Table 1. Chemical compositions of the tested AM50+Er alloys (\%, mass fraction).

\begin{tabular}{ccccccccc}
\hline Alloy & $\mathrm{Al}$ & $\mathrm{Mn}$ & $\mathrm{Er}$ & $\mathrm{Zn}$ & $\mathrm{Si}$ & $\mathrm{Cu}$ & $\mathrm{Ni}$ & $\mathrm{Mg}$ \\
\cline { 2 - 9 } AM50 & 4.86 & 0.28 & 0 & 0.12 & 0.016 & 0.0015 & 0.0008 & Bal. \\
AM50+0.5\% Er & 4.85 & 0.28 & 0.48 & 0.12 & 0.013 & 0.0012 & 0.0005 & Bal. \\
AM50+1\% Er & 4.83 & 0.27 & 0.96 & 0.11 & 0.012 & 0.0012 & 0.0005 & Bal. \\
AM50+1.5\% Er & 4.80 & 0.27 & 1.46 & 0.12 & 0.011 & 0.0010 & 0.0005 & Bal. \\
\hline
\end{tabular}

\subsection{Weightlessness corrosion test}

The size of the $10 \times 10 \times 12 \mathrm{~mm}$ samples for the weightlessness corrosion test were cut with a linear cutting machine. Their surfaces were sanded with 300,600, and 1000 grit waterproof abrasive paper. The samples were cleaned with water and anhydrous ethanol in the ultrasonic cleaning machine. Then, they were weighed with a ten thousand scale, before being tied with fishing line and lifted into the corrosion solution. In this experiment, all etching liquids containing $\mathrm{Cl}$ ions were of 3.5 wt. \%. The $\mathrm{NaCl}$ solution was saturated with $\mathrm{Mg}(\mathrm{OH}) 2$, which used the analytical reagent and distilled water; that is, the $3.5 \% \mathrm{NaCl}$ solution was first prepared, and then $\mathrm{Mg}(\mathrm{OH}) 2$ powder was put into the solution to form a supersaturated solution. The purpose was to keep the $\mathrm{pH}$ value of the solution constant at 10.3 , so as to ensure a constant corrosion rate. The corrosion time of the weightlessness test samples corresponded to $24,72,168,264,336$, or $432 \mathrm{~h}$. At each time point, three samples were taken out as a group. Subsequently, the corrosion products were cleaned with a silver nitrate solution of chromic acid (CrO3 concentration 16.5 wt. \%, and AgNO3 0.83 wt. \%), then washed with water and alcohol in turn in an ultrasonic wave, and finally weighed. The corrosion weight loss rate was calculated as follows:

$$
v_{t}=\frac{m_{0}-m_{t}}{s \cdot t}\left(g \cdot y^{-1} \cdot \mathrm{cm}^{-2}\right)
$$

where, $\mathrm{m}_{0}$ and $\mathrm{mt}$ refer to the sample weights before and after the immersion corrosion, respectively $(\mathrm{g})$; $\mathrm{t}$ is the corrosion time in years; and $\mathrm{S}\left(=6.4 \mathrm{~cm}^{2}\right)$ refers to the sample corrosion area. 


\subsection{Corrosion Residual Strength (CRS) test}

The CRS test samples were cut from the casting sample into sizes of $100 \times 12 \times 12 \mathrm{~mm}$, and then processed into the tensile samples with the size shown in Fig. 1. using the CNC lathe. The samples were immersed in the corrosion solution, with the non-working area protected, and three samples were taken out at a time at 24,72, 168, 264, and $432 \mathrm{~h}$ and then stretched by the SUNS (Shenzhen suns zongheng technology co. LTD, Shenzhen, China) tensile test machine.

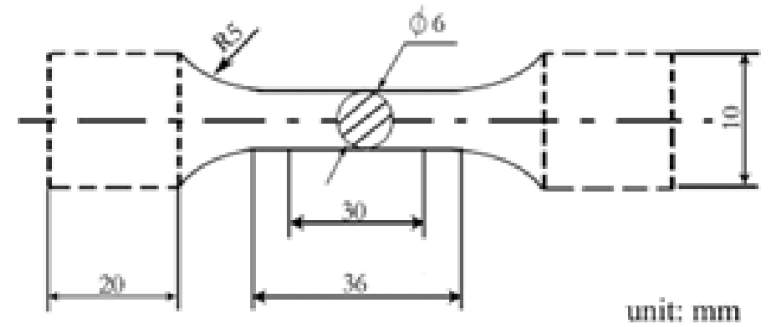

Fig. 1. Schematic drawing of the corrosion residual strength (CRS) tensile test samples.

\subsection{Analysis of microstructure and fractography}

The observed microstructure samples were polished by waterproof abrasive paper with 300 , 600,1000 and 2000 grit, then polished and etched by alcohol nitrate for $30 \mathrm{~s}$. The fracture microstructure was observed by using scanning electron microscope (SEM) equipment.

\section{Results and discussion}

\subsection{Microstructure}

Fig. 2 shows shows the SEM microstructure of the alloy. There was mainly $\alpha-M g, \beta-M_{17} \mathrm{Al}_{12}$ phase, with a small amount of acicular Al-Mn phase present in the AM50 magnesium alloy. After the addition of rare earth Er, two new phases of $\mathrm{Al}_{3} \mathrm{Er}$ and $\mathrm{Al}-\mathrm{Er}-\mathrm{Mn}$ appeared. With the increase of the amount of Er added from $0.5 \%$ to $1.0 \%$, the quantity of the $\mathrm{Al}_{3} \mathrm{Er}$ phase gradually increased. At the same time, the volume of the $\beta-\mathrm{Mg}_{17} \mathrm{Al}_{12}$ phase decreased. Meanwhile, grain refinement of $\alpha-\mathrm{Mg}$ was observed. When the addition amount of Er increased to $1.5 \mathrm{wt}$ \%, both the volume and the quantity of the Al-Er phase in the microstructure were increased, and the quantity of the $\beta-\mathrm{Mg}_{17} \mathrm{Al}_{12}$ phase further reduced. 

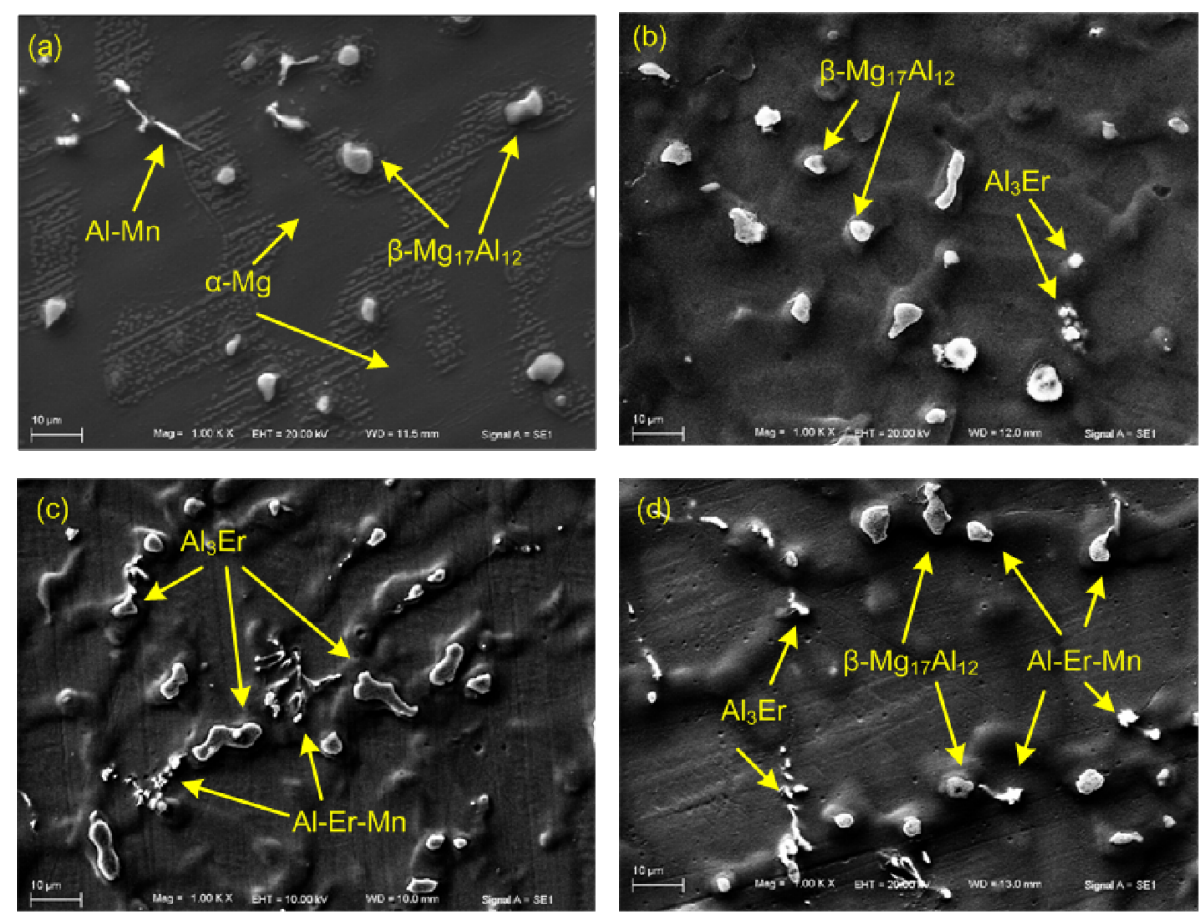

Fig. 2. The scanning electron microscope (SEM) morphologies of the AM50 magnesium alloy with the addition of (a) $0 \%$, (b) $0.5 \%$, (c) $1 \%$, and (d) $1.5 \%$ Er.

\subsection{Weightlessness rate}

Fig. 3 shows a comparison diagram of the weightlessness corrosion rate of the alloy with different rare earth Er additions. The influence of the addition of $\mathrm{Er}$ on the corrosion resistance of the AM50 magnesium alloy is in the order of $0.5 \%>1.5 \%>1.0 \%>0$. The corrosion weight loss of the AM50 magnesium alloy is about 5 times that of the alloy with Er, indicating that the addition of rare earth Er plays a very good role in improving the corrosion resistance of AM50 magnesium alloy. When the amount of $1 \%$ is added, the corrosion rate is larger at $24 \mathrm{~h}$, while it is approximate in the other time points. The corrosion rate was ranked as $24 \mathrm{~h}>72 \mathrm{~h}>168 \mathrm{~h}$, indicating that the corrosion rate of the alloy decreases with extension of the corrosion time. This is mainly due to the continuous thickening of the film layer on the sample surface as the corrosion progresses, resulting in a continuous decline in the corrosion rate. The corrosion mode of the AM50 magnesium alloy in the $\mathrm{NaCl}$ solution was that of pitting, and the weightlessness corrosion rate measured the comprehensive process of the complex chemical and electrochemical reactions. When the amount of Er was either $1.0 \%$ or $1.5 \%$, a larger volume of $\mathrm{Al}_{3} \mathrm{Er}$ phase fell off during the cleaning process of the samples, which further increased the amount of measured data. 


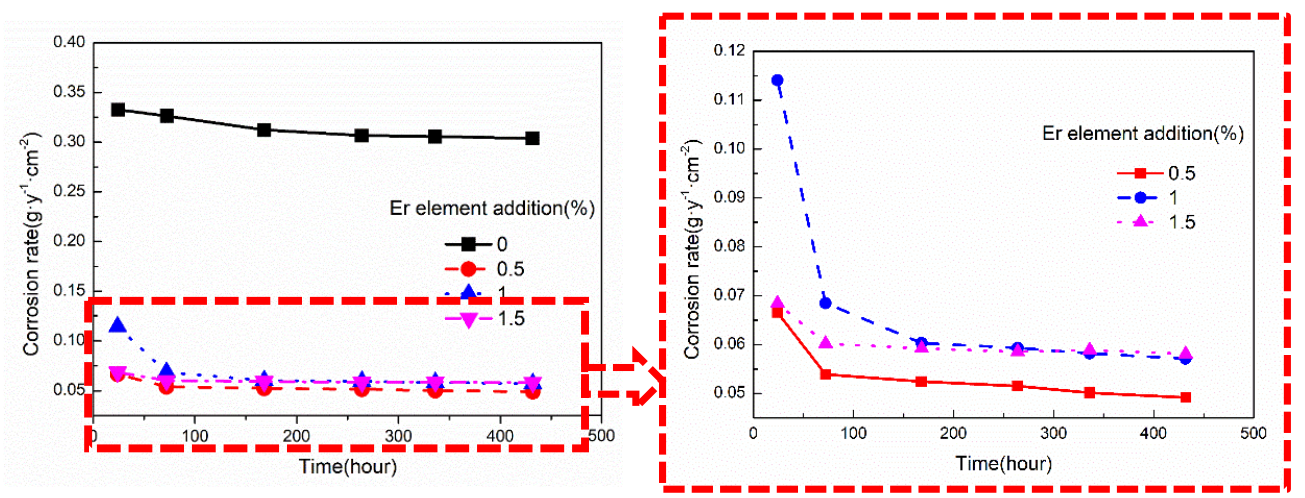

Fig. 3. The weightlessness rate results of the AM50 magnesium alloy with the addition of $0 \%, 0.5 \%$, $1 \%$, and $1.5 \%$ Er.

Fig. 4 shows the surface morphologies of the corrosion samples with different amounts of rare earth $\mathrm{Er}$ modified in $3.5 \% \mathrm{NaCl}$ solution for $72 \mathrm{~h}$. Compared to the AM50 magnesium alloy without Er, the number of corrosion pits on the surface of the samples with Er was significantly reduced. Fig. 5 shows the surface morphologies of the CRS samples of $0.5 \mathrm{wt}$ \% Er added after corrosion for $24,72,168,264,336$ and $432 \mathrm{~h}$ in the $3.5 \% \mathrm{NaCl}$ solution. With extension of the corrosion time, the number of pits gradually increased and connected to each other. The quality of magnesium alloy surface film layer could significantly affect the nucleation of corrosion pit on it. First, after the addition of rare earth Er, the microstructure of magnesium alloy was refined. Second, the formation of Al3Er phase consumed $\mathrm{Al}$ in $\beta$ $\mathrm{Mg} 17 \mathrm{Al12}$, which leaded to reduce the quantity of $\beta-\mathrm{Mg}_{17} \mathrm{Al}_{12}$ phase. That inhibited the cathode reaction, and improved the corrosion resistance. Third, as a surface-active element, Er element could improve the quality of the alloy surface films and enhance the corrosion resistance.
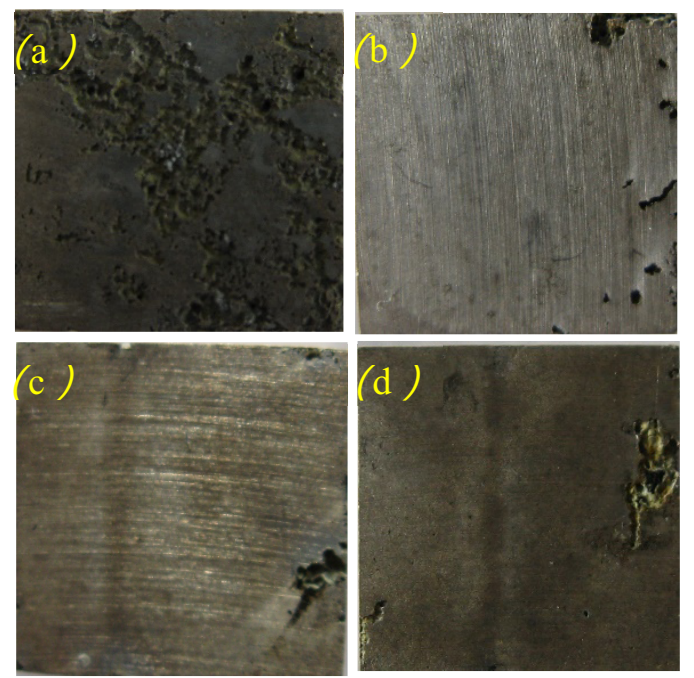

Fig. 4. The surface corrosion morphologies of the weightlessness tested samples with $0 \%$ (a), $0.5 \%$ (b), $1 \%$ (c) and $1.5 \%$ (d) Er after immersion for $72 \mathrm{~h}$. 


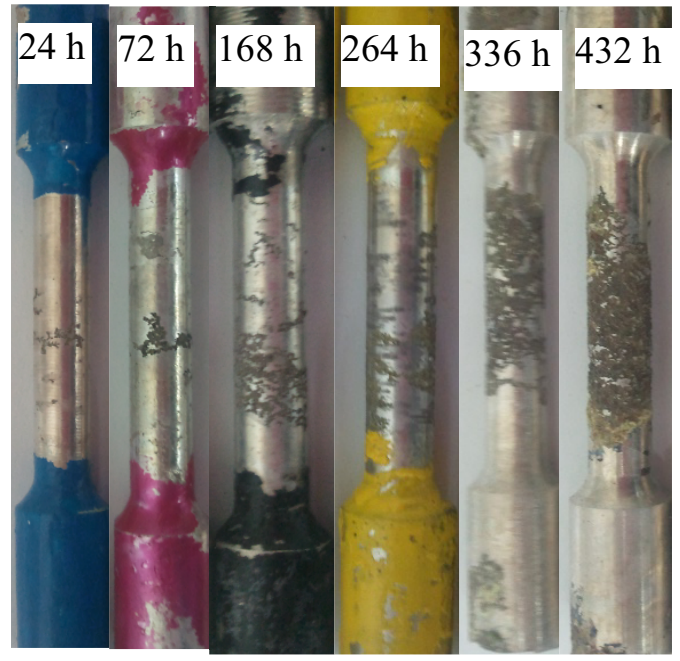

Fig. 5. The surface corrosion morphologies of the AM50+0.5\% Er tensile test samples after immersion for $24,72,168,264,336$ and $432 \mathrm{~h}$ in $3.5 \% \mathrm{NaCl}$ solution.

\subsection{Corrosion residual strength (CRS)}

Fig. 6a shows the CRS results of the Er-modified AM50 magnesium alloys after being corroded for 24,72 and $168 \mathrm{~h}$ in $3.5 \% \mathrm{NaCl}$ solution. It was found that after adding rare earth Er, the CRS results of the alloy at each time point were higher than that of not adding any Er. Moreover, as the amount of Er increased, the tensile strength of the alloy increased slightly at $0 \mathrm{~h}$. This is because the addition of rare earth Er plays a role in the strengthening of the solid solution and in grain refinement. Moreover, with the increase of Er, a rare earth phase $\left(\mathrm{Al}_{3} \mathrm{Er}\right)$ with better performance was distributed at the grain boundary, which prevented the crack from expanding and improved the tensile strength of the alloy. However, at 24 and 72 $\mathrm{h}$, the residual strength of the alloy with the addition of Er was not obviously superior to that without Er, and only the addition of $0.5 \%$ resulted in good CRS. It can be seen from the weightless corrosion results that the corrosion rate tended to be stable after $168 \mathrm{~h}$. However, CRS attenuation of the AM50 magnesium alloy with the addition of $0.5 \%$ Er was at the minimum (35 MPa) after $168 \mathrm{~h}$ of corrosion (Fig. 6). After the increase of rare earth Er, although its attenuation was not significantly higher than that without Er, the absolute value of CRS was still higher than that without Er. In summary, rare earth Er plays a good role in improving the CRS of AM50, and the optimal addition amount is $0.5 \%$.

Fig. $6 \mathrm{~b}$ shows the engineering stress-strain tensile curves of the AM50 magnesium alloy with $0.5 \% \mathrm{Er}$ added into $3.5 \% \mathrm{NaCl}$ solution at the corrosion time of $24,72,168,264,336$ and $432 \mathrm{~h}$, respectively. The results show that the overall shape of the tensile curve changed little, and that the plastic zone became shorter as the corrosion time increased, indicating that the deformation capacity and fracture strength of the alloy decreased. Judging from the shape of the curve, the corrosion in $3.5 \% \mathrm{NaCl}$ solution did not change the fracture mode of the alloy, but rather seriously affected its deformation capacity. 
(a)

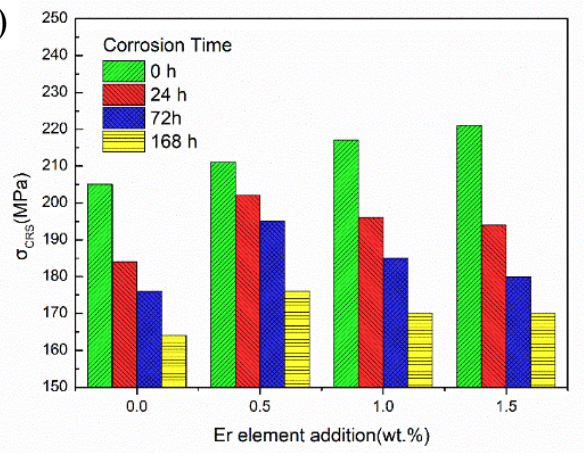

(b)

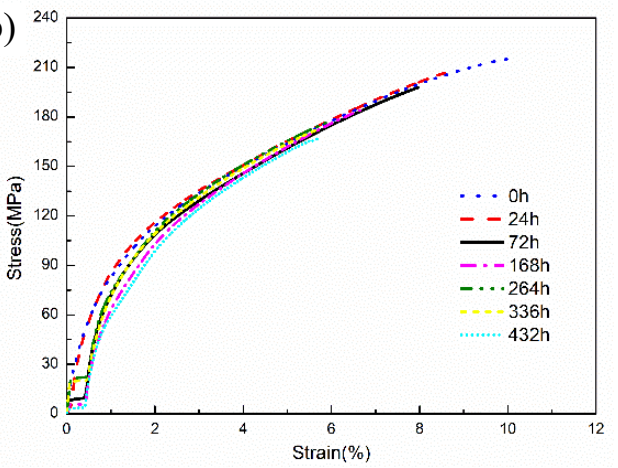

Fig. 6. (a) Corrosion residual stress of the AM50 magnesium alloy with the addition of $0 \%, 0.5 \%$, $1 \%$, and $1.5 \%$ Er; (b) the engineering stress-strain curves of $0.5 \%$ Er modified AM50 magnesium alloy after different corrosion times.

Fig. 7 shows the tensile fracture morphology of the AM50 magnesium alloy with the addition of rare earth $\mathrm{Er}$ of $0 \%, 0.5 \%, 1.0 \%$ and $1.5 \%$, respectively. As can be seen from the figure, the fracture was composed of cleavage steps and secondary cracks. As the addition of Er increased, granular rare earth compounds gradually appeared in the fracture, and the volume and quantity of these compounds gradually increased. After the addition of rare earth Er, the fracture mode of the AM50 magnesium alloy remained as cleavage fracture - namely, brittle fracture-which was consistent with the results of the stress-strain tensile curves. As there was a large plane in the fracture, the crack mainly expanded along the $\alpha-\mathrm{Mg}$ phase boundary during the fracture. As the most important component phase in the alloy, the hardness of the $\alpha$-Mg phase was lower than that of the other phases; thus, it was easy to form transgranular fracture through the interior of the $\alpha-\mathrm{Mg}$ phase. This was mainly determined by the microscopic structure of the $\alpha-\mathrm{Mg}$ phase and the mechanism of deformation. The $\alpha-$ $\mathrm{Mg}$ phase was a magnesium solid solution that solutes a small amount of dissolved $\mathrm{Al}$ atoms[20]. However, it had a close-packed hexagonal structure. During the tensile process, microcracks formed preferentially at the (0001) surface[9, 21]. Parallel cracks at different heights formed cleavage steps through secondary cleavage or tearing. When the alloy was under stress, internal stress formed at the junction of the $\alpha-\mathrm{Mg}$ phase and the other phases. When the internal stress exceeded a certain value, a large number of dislocations were formed. As the load increased, the dislocation expanded along the low-energy interface, which led to the formation of microcracks. When the microcracks were hindered by solid solution atoms or other phases in the process of growth, it changed the direction of advance; thus, a tearing edge appeared at the grain boundaries of the $\alpha-\mathrm{Mg}$ phase. 

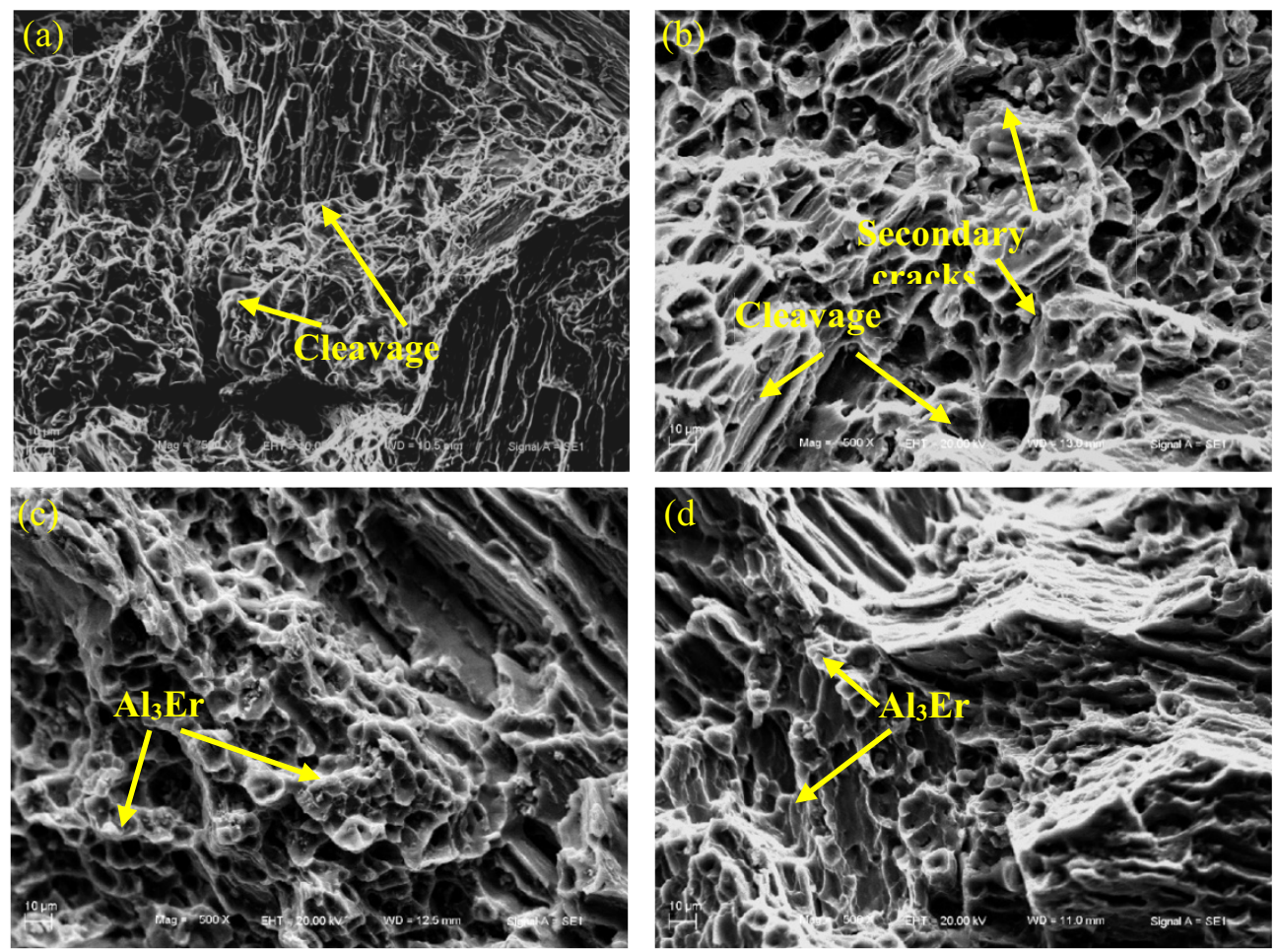

Fig. 7. Fracture morphologies of the AM50 magnesium alloy with the addition of $0 \%(\mathrm{a}), 0.5 \%(\mathrm{~b})$, $1 \%(\mathrm{c})$, and $1.5 \%(\mathrm{~d}) \mathrm{Er}$.

Fig. 8 shows the exterior fracture morphologies of the $0.5 \%$ Er modified AM50 magnesium alloy tensile samples corroded in $3.5 \% \mathrm{NaCl}$ solution for 72 and $168 \mathrm{~h}$. There were corrosion pits at the edge of the fracture, and inside the pit, there were some unwashed white corrosion products. Moreover, large-sized microcracks were observed. The appearance of these microcracks proved that during the tensile process, stress concentration appeared in the pits. Furthermore, the crack size was larger than that in the middle of sample, which also indicated that the pits resulted in fracture under lower stress conditions.
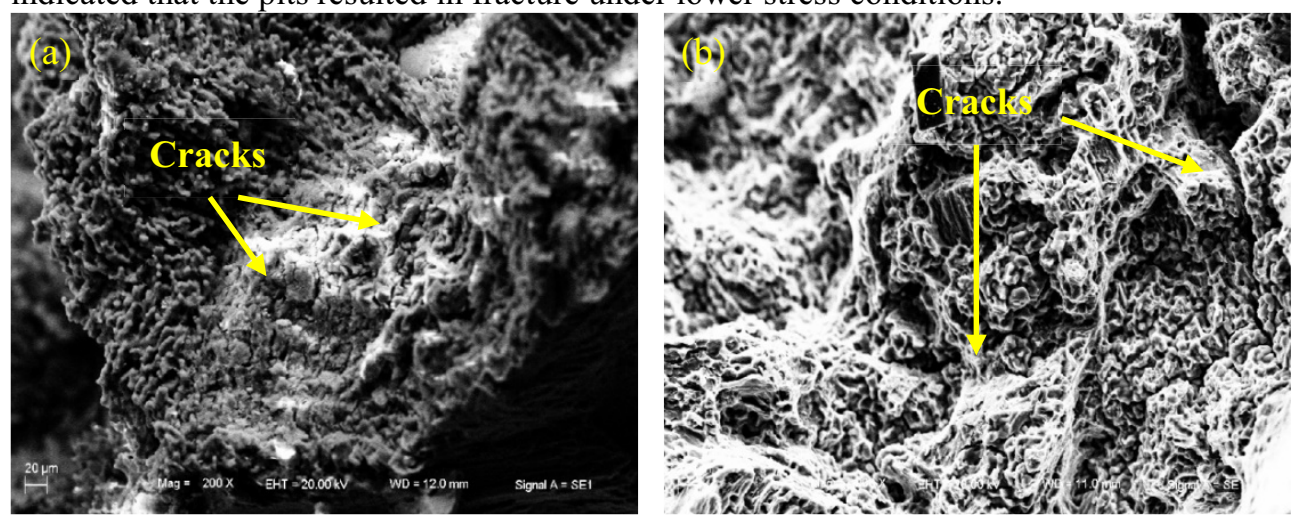

Fig. 8. Exterior fracture morphologies of the AM50 magnesium alloy tensile samples with $0.5 \% \mathrm{Er}$ after corrosion for 72 (a) and $168 \mathrm{~h}$ (b) in $3.5 \% \mathrm{NaCl}$ aqueous solution.

The addition of rare earth element Er not only improved the structure of the alloy, but also changed the phase composition and distribution in the alloy structure and refined the 
grains. Further more, Er is a surface-active element, it was easily adsorbed at the growth tip, and thus inhibited the growth of the $\beta-\mathrm{Mg}_{17} \mathrm{Al}_{12}$ phase and improved its dispersion. Therefore, after the addition of rare earth Er, the microstructure of the alloy changed, resulting in a change of corrosion resistance and of the mechanical properties.

Although rare earth elements improve the corrosion resistance of magnesium alloys overall, the CRS properties cannot be analyzed and explained overall. The corrosion dynamic mechanical properties of magnesium alloys are a complex problem. The corrosion rate, the corrosion form, and the development of corrosion pits have important effects on the change of mechanical properties. The addition of rare earth Er does not change the appearance form of the AM50 magnesium alloy when it is corroded, which remains that of pitting corrosion. The nucleation and growth of pitting corrosion change the surface morphology of magnesium alloys. Stress concentration occurs at the bottom of the corrosion pit, and with the development of pitting corrosion, the local effective cross-sectional area of the sample continuously decreases. This is the main reason why the apparent strength of the alloy continued to decrease, even though the strength of the alloy did not change, or even increased slightly. Therefore, $0.5 \%$ Er was the best quantity to add to improve the dynamic corrosion mechanical properties of the AM50 magnesium alloy in this paper.

\section{Conclusion}

The effect of the addition of Er (mass fraction of $0 \%, 0.5 \%, 1 \%$, and $1.5 \%$ ) on the dynamic corrosion mechanical properties of the AM50 magnesium alloy was studied. The main conclusions are:

1) The corrosion resistance of the addition of rare earth Er to the alloy was $0.5 \%>1.5 \%>$ $1.0 \%>0 \%$. Furthermore, the corrosion rates decreased in $432 \mathrm{~h}$.

2) The CRS results within $168 \mathrm{~h}$ show that the strength after the addition of $0.5 \%$ Er was the highest and the decline rate was the smallest.

3) The addition of rare earth Er did not change the fracture form of the alloy, which remained as quasi-cleavage.

This research was supported by National Natural Science Foundation Youth Science Foundation Project of China (No.61901007); Science and Technology Research Project of Education Department of Jilin Province, China(No. JJKH20200040KJ; JJKH20210036KJ) ; Natural Science Foundation of Jilin Province (No. YDZJ202101ZYTS172); Science and Technology project of Beihua University (No. 201901015;201901005); National College Students Innovation and Entrepreneurship Training Program of China (No. 201910201062). Young Science and Technology Innovation Team of Beihua University (No. 202016003).

\section{References}

1. Song Y, D Shan and E H Han 2017 Pitting corrosion of a rare earth Mg alloy GW93 (Journal of Materials Science \& Technology vol 33) pp 954-960

2. Song G, A L Bowles and D H Stjohn 2004 Corrosion resistance of aged die cast magnesium alloy AZ91D (Materials Science \& Engineering A vol 366) pp 74-86

3. Tao Z, L Ying and F Wang 2006 Roles of $\beta$ phase in the corrosion process of AZ91D magnesium alloy (Corrosion Science vol 48) pp 1249-1264

4. Höhn S, S Virtanen and A R Boccaccini 2019 Protein adsorption on magnesium and its alloys: A review (Applied Surface Science vol 464) pp 212-219

5. Zhang J and Z Zhang 2004 Magnesium alloys and applications Chemical industry Press) 
6. Wang L, B P Zhang and T Shinohara 2010 Corrosion behavior of AZ91 magnesium alloy in dilute $\mathrm{NaCl}$ solutions (Materials \& Design vol 31) pp 857-863

7. Song G L and Z Q Xu 2010 The surface, microstructure and corrosion of magnesium alloy AZ31 sheet (Electrochimica Acta vol 55) pp 4148-4161

8. Kruger J 2001 Magnesium Alloys: Corrosion

9. Wang B J, D K Xu, S D Wang, L Y Sheng, R-C Zeng and E-h Han 2019 Influence of solution treatment on the corrosion fatigue behavior of an as-forged $\mathrm{Mg}-\mathrm{Zn}-\mathrm{Y}-\mathrm{Zr}$ alloy (International Journal of Fatigue vol 120) pp 46-55

10. Li Q A, X Li, Q Zhang and J Chen 2010 Effect of rare-earth element Sm on the corrosion behavior of Mg-6Al-1.2Y-0.9Nd alloy (Rare metals vol 29) pp 557-560

11. Huang L, Y Huang, C Wang and Z Wei 2002 Study on corrosion product film of magnesium-aluminum alloys containing rare-earth element in $\mathrm{NaCl}$ solution (Journal of Chinese Society for Corrosion \& Protection vol 22) pp 167-171

12. Kliškić M, J Radošević, S Gudić and V Katalinić 2000 Aqueous extract of Rosmarinus officinalis L. as inhibitor of Al-Mg alloy corrosion in chloride solution (Journal of Applied Electrochemistry vol 30) pp 823-830

13. Yang M, X Liu, Z Zhang, Y Song and L Bai 2019 Effect of adding rare earth elements Er and Gd on the corrosion residual strength of magnesium alloy (Open Physics vol 17) pp 373-380

14. Liu W, F Cao, L Zhong, L Zheng, B Jia, Z Zhang and J Zhang 2015 Influence of rare earth element $\mathrm{Ce}$ and $\mathrm{La}$ addition on corrosion behavior of AZ91 magnesium alloy (Materials \& Corrosion vol 60) pp 795-803

15. Zhang L-n, R Jia, D Li, W Zhang and F Guo 2015 Effect of intermetallic phases on corrosion initiation of AZ91 alloy with rare earth Y addition (Journal of Materials Science \& Technology vol 31) pp 504-511

16. Wang Q, Y Liu, S Fang, Y Song, D Zhang, L Zhang and C Li 2010 Evaluating the improvement of corrosion residual strength by adding $1.0 \mathrm{wt} . \%$ yttrium into an AZ91D magnesium alloy (Materials Characterization vol 61) pp 674-682

17. Li C, Y Liu, Q Wang, L Zhang and D Zhang 2010 Study on the corrosion residual strength of the 1.0 wt.\% Ce modified AZ91 magnesium alloy (Materials Characterization vol 61) pp 123-127

18. Yang M, Z Zhang, Y Liu and X Han 2016 Corrosion and mechanical properties of AM50 magnesium alloy after modified by different amounts of rare earth element Gadolinium (Open Physics vol 14) pp 444-451

19. Yang M, Y Liu, J Liu and y Song 2014 Corrosion and mechanical properties of AM50 magnesium alloy after being modified by $1 \mathrm{wt} . \%$ rare earth element gadolinium (Journal of Rare Earths vol 32) pp 558-563

20. Peng X, Y Li, Q Guo and G Xu 2018 Effects of enhanced solution treatment on stress corrosion behavior of Al-Zn-Mg-Cu Alloy (Jom vol 70) pp 2692-2697

21. Yin Z, F Liu, D Song, S He, J Lin and F Yu 2018 Stress corrosioncracking of a forged $\mathrm{Mg}-\mathrm{Al}-\mathrm{Zn}$ Alloy with different surface conditions (Journal of Chemistry vol 2018) pp 